\title{
Development of a Conceptual Model of Adherence to Oral Anticoagulants to Reduce Risk of Stroke in Patients with Atrial Fibrillation
}

\author{
T. Michelle Brown, PhD; Kimberly Siu, MD, MPH; David Walker, PhD; \\ Manel Pladevall-Vila, MD, MS; Stephen Sander, PharmD; and Margaret Mordin, MS
}

\begin{abstract}
BACKGROUND: Oral anticoagulant $(0 A)$ medication is the recommended therapy for reducing the risk of thromboembolic complications in patients with atrial fibrillation $(\mathrm{AF})$, and warfarin is the medication most frequently used. However, nonadherence associated with $O A$ medications may lead to considerable health risks. A conceptual model of $O A$ medication adherence in patients with AF could clarify factors affecting adherence, thereby assisting in the development and structuring of adherence-promotion programs. To our knowledge, such a model, driven by information obtained directly from patients, has never been developed.
\end{abstract}

OBJECTIVE: To develop a conceptual model of adherence to OA medication based on a literature review and patient feedback via qualitative research among patients with AF.

METHODS: A literature search was conducted of English-language articles published between the years 2005 and 2010 that related to factors affecting $0 \mathrm{~A}$ medication adherence, excluding articles pertaining to AF associated with mechanical heart valve replacement. To expand on the literature review findings, 4 focus groups totaling 38 participants aged 60 years or older, diagnosed with nonvalvular $\mathrm{AF}$, and currently taking any $0 \mathrm{~A}$ medication were conducted in 2011. Participants completed the Modified Morisky Scale (MMS), with subscales measuring motivation and knowledge, and were asked about daily processes and behaviors related to taking $0 \mathrm{~A}$ medication. The identification of focus group themes was based on the frequency of participant report and endorsement; themes were spontaneously mentioned or supported by at least 2 people in each of at least 3 focus groups. Model concepts, based on focus group themes and factors identified in the literature review, were determined by the consensus of 3 authors.

RESULTS: 181 publications were identified; 30 were selected for full-text review. The focus group participants had a mean age of 69.9 years. Most participants reported a diagnosis of hypertension $(86.8 \%, n=33)$, high cholesterol $(50.0 \%, n=19)$, heart disease or chronic heart failure $(31.6 \%$, $\mathrm{n}=12)$, or diabetes $(28.9 \%, \mathrm{n}=11)$. Most $(89.5 \%, \mathrm{n}=34)$ were taking warfarin. About one-half $(52.6 \%, n=20)$ had been taking an $0 A$ medication for less than 5 years. 0 n the MMS, $78.9 \%$ of participants reported high levels of motivation, and $100 \%$ reported high levels of knowledge. Four concepts emerged from the focus groups and were supported by the literature for inclusion in the model: (a) knowledge base of the disease and continued reinforcement (i.e., health care professional reinforcement); (b) shortterm and long-term motivation (e.g., avoidance of negative health consequences); (c) personalized system, habit formation, and system adaptation (e.g., developing a routine or external reminders); and (d) self-efficacy loop (i.e., the personalized system and its adaptability are reinforced as patients become more consistent, confident, and adherent). The literature review also suggested other factors that may also affect patient adherence (e.g., demographic, psychosocial, cognitive).
CONCLUSION: Adherence in patients with AF is complex and involves multiple factors, some specific to each individual and others more general. This model identifies an adherence process that can guide opportunities for effective interventions, such as educational and behavioral programs targeted at these processes, to improve patient adherence to $0 \mathrm{~A}$ medication.

J Manag Care Pharm. 2012;18(5):351-62

Copyright $\odot 2012$, Academy of Managed Care Pharmacy. All rights reserved.

\section{What is already known about this subject}

- Atrial fibrillation (AF) affects approximately 3 million adults in the United States. It is accompanied by high costs and morbidity, and hospitalizations associated with $\mathrm{AF}$ are expected to continue to increase.

- Framingham Heart Study outcomes suggest that the age-adjusted 2-year incidence of stroke among patients with AF is approximately 5 times that of people without AF.

- Warfarin is a highly common and an effective oral anticoagulant (OA) medication to prevent thromboembolic complications of AF. However, among adults aged 65 years or older, warfarin is the most common drug implicated in U.S. emergency hospitalizations associated with recognized adverse events, and warfarin nonadherence rates of 22\%-32\% have been reported.

\section{What this study adds}

- This study used a focus group technique coupled with a literature review to incorporate the perspectives of patients with AF and to explore the many interacting factors and individual patient needs and differences potentially affecting the OA medication adherence process.

- A conceptual model identifies an adherence process that can guide opportunities for effective interventions, such as educational and behavioral programs targeted at these processes, to improve adherence to OA medications among patients with AF.

- Key concepts identified by the focus group and supported by the literature review included (a) knowledge about the disease and continued reinforcement by health care professionals; (b) shortterm and long-term motivation (e.g., avoidance of negative health consequences); (c) personalized system, habit formation, and system adaptation (e.g., developing a routine or external reminders); and (d) self-efficacy loop (i.e., reinforcement of the personalized system and its adaptability as patients become more consistent, confident, and adherent). 
A trial fibrillation (AF) affects approximately 3 million adults in the United States. ${ }^{1}$ The rate of AF increases with age, from less than $1 \%$ among persons aged younger than 60 years to approximately 9\% among persons aged older than 80 years. $^{2} \mathrm{AF}$ is accompanied by high costs and morbidity. The number of hospitalizations associated with $\mathrm{AF}$ is expected to continue to increase, following an already observed 144\% increase from 1985 to 1999 among adults aged 35 years or older. ${ }^{3} \mathrm{AF}$ is also a major risk factor for stroke. Based on the Framingham Heart Study, the age-adjusted 2-year incidence of stroke among patients with $\mathrm{AF}$ is approximately 5 times that of people without $\mathrm{AF}^{4}$

Warfarin (Coumadin) is an effective medication commonly used to prevent thromboembolic complications of $\mathrm{AF}^{5}$ although problems with both low and high international normalized ratios (INRs) ${ }^{6}$ and issues with adherence have been reported. ${ }^{7}$ Major or minor bleeding is the most common side effect of warfarin and occurs in up to $41 \%$ of treated patients, with rates of major bleeding of about $1 \%-8 \%$ per year. ${ }^{8,9}$ Among adults aged 65 years or older, warfarin is the most common drug implicated in U.S. emergency hospitalizations associated with recognized adverse events. ${ }^{10}$ Although major bleeding is of substantial concern, even minor bleeding can lead to cessation of medication. ${ }^{8}$

Medication adherence (or compliance) is generally defined as "the extent to which patients take medications as prescribed by their health care providers." ${ }^{11}$ Nonadherence includes not only cessation of medication therapy but also taking the medication other than as prescribed (i.e., underadherence, overadherence, or not taking the dose at the prescribed time). Most studies report medication adherence as a percentage of doses taken out of those prescribed over a specific period of time. While there is no general consensus on what constitutes adherence or nonadherence, studies show that nonadherence to oral anticoagulant (OA) medication is generally problematic in practice. In a longitudinal U.S. cohort study of 1,005 patients with $\mathrm{AF}$ and taking warfarin, there was a 32\% reduction (from $65 \%$ to $44 \%$ ) in the number of patients taking warfarin after 30 months. ${ }^{12}$ In a prospective study of warfarin adherence at 3 Pennsylvania-based anticoagulation clinics, both underadherence and overadherence were measured among a sample of 145 patients. The mean percentage of nonadherent days was $21.8 \%$ as measured by electronic medication event monitoring. ${ }^{13}$

Current research suggests that many factors are associated with patient nonadherence to OA medication. ${ }^{14}$ However, the bulk of this literature focuses on the associated factors or the impact of nonadherence, as obtained from database analyses or measures not developed with patient input, and does not describe the process or drivers of adherence. To understand the process of patient adherence, qualitative research with patients is needed.

A conceptual model can visually depict the process of how different influencing factors that affect patient outcomes relate to one another. ${ }^{15}$ For example, in a review article that identified many factors associated with nonadherence in older adults, Murray et al. (2004) developed a conceptual model of general medication adherence to improve adherence, assist in adherence research, and facilitate the development of multidimensional adherence-improvement interventions. ${ }^{16}$ Murray et al. concluded from an extensive literature search that older adults are at special risk due to the burden of multiple chronic diseases and age-related factors, such as cognitive impairment and other environmental and social factors.

Given the serious consequences of OA medication nonadherence, ${ }^{5}$ the special needs of this older adult population, and the likely added complexity of influential demographic and social factors, additional information is needed on the OA medication adherence process from the patient perspective. To our knowledge, no research exists related to the development of a conceptual model of adherence specific to OA medication or a model developed directly with feedback from patients with AF. This patient-centered approach may become increasingly important because new OA medications that do not require regular INR testing have recently been approved and may change patient adherence behaviors in ways that have not yet been studied. The current study aimed to explore and understand what helps patients with AF take OA medication as prescribed and, specifically, to develop a conceptual model of the adherence process from a literature review and qualitative research with a nonprobability sample of patients. This study was designed to focus on nonvalvular AF (NVAF), the most common form of AF, ${ }^{17}$ however, "AF" will be used throughout the remainder of this article.

\section{Methods}

\section{Literature Review}

A literature review was performed in PubMed for publications between the years 2005 and 2010 relating to factors that affect OA medication adherence among patients with AF. The following text strings and MeSH terms were searched among English-language publications and studies conducted among humans: "medication adherence" [MeSH] OR "patient compliance" [MeSH] OR "treatment refusal" [MeSH] OR "attitude to health" [MeSH]; and "anticoagulants" [MeSH] OR "coumarins" [MeSH]. A total of 181 publications were identified (Figure 1). Among these publications, articles selected for further review included those that reported on factors that affect adherence to OA medication. A total of 30 articles were included in the literature review. Of note, due to the time frame of this review and highly prevalent use of warfarin, all identified articles related to OA adherence involved the use of warfarin.

\section{Focus Groups}

Four focus groups were conducted in 2 U.S. East coast cities in 2011 among a convenience sample of patients with AF. Recruitment was initiated after review and approval by the 
Development of a Conceptual Model of Adherence to Oral Anticoagulants to Reduce Risk of Stroke in Patients with Atrial Fibrillation

\section{FIGURE 1 Flow Chart Representing Literature Inclusion and Exclusion}

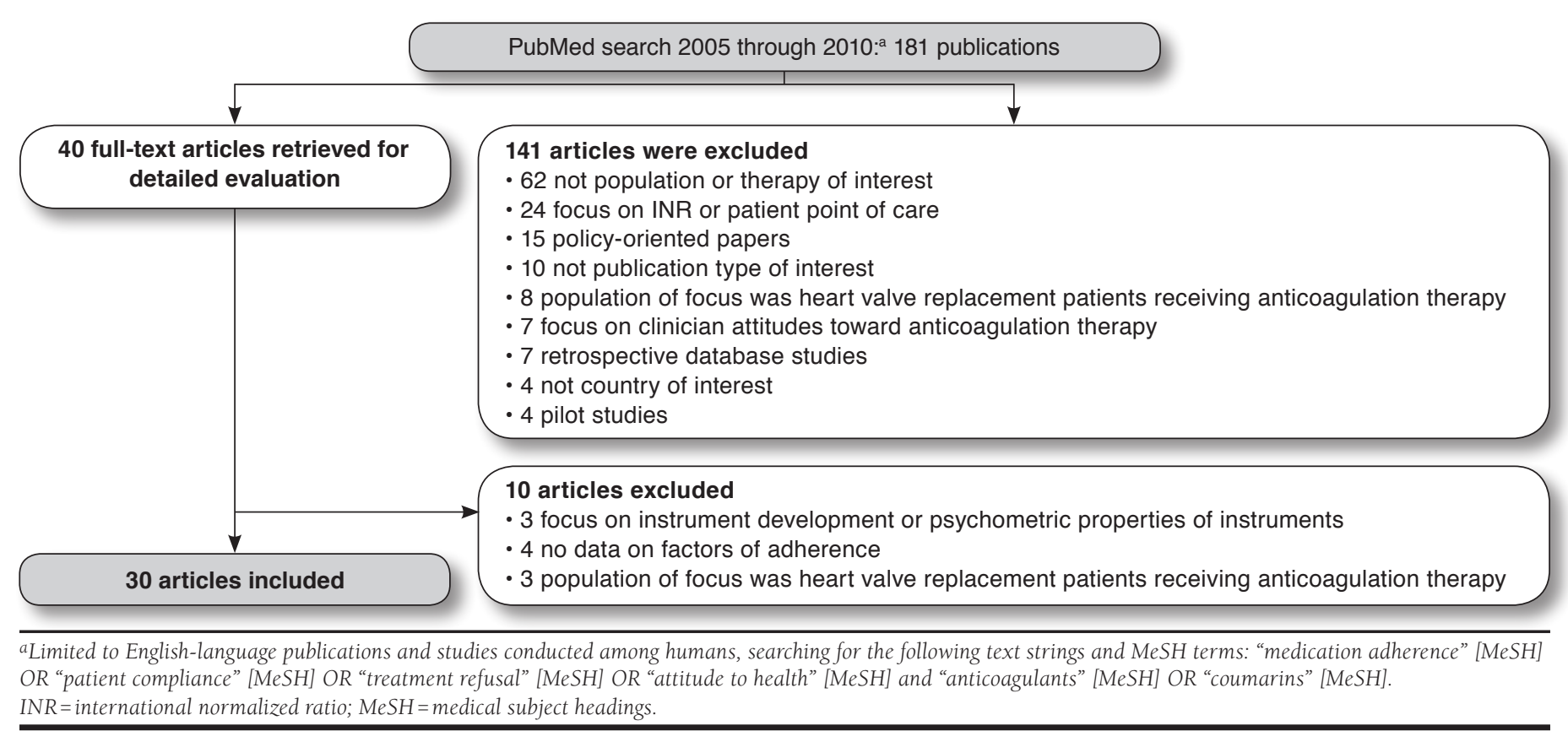

Research Triangle Institute Institutional Review Board. Trained recruiters from 2 qualitative research firms contacted potential participants from their existing databases of individuals interested in participating in qualitative research to find those who were both eligible and interested in participating in the focus groups. Potential participants self-reported all information and were eligible for participation if they met the following inclusion criteria: aged at least 60 years; physician diagnosis of AF for at least 6 months; current or recent use of an OA medication in the past year (i.e., warfarin, clopidogrel bisulfate, dabigatran etexilate, dipyridamole); able to provide informed consent; and able to read and understand English. Patients were excluded if they had a stroke in the past 6 months or had ever undergone heart valve replacement surgery (i.e., assuming that patients may not know if they have NVAF specifically, they were asked about previous heart valve replacement surgery so that only those not reporting surgery would qualify). All qualified individuals were extended an invitation to participate in the focus group. Qualifying individuals who participated in the focus groups were compensated $\$ 100$ for their time.

Prior to the group discussion, participants were asked to complete the 6-item Modified Morisky Scale (MMS) to assess self-reported patient adherence to OA medication. Participants were asked to answer the questions on the MMS based on their current use and experience with their OA medications. The MMS is a version of the validated 4-item Morisky scale originally developed to assess adherence related to antihypertension medication ${ }^{18}$ and was later used among patients taking longterm warfarin therapy. ${ }^{19}$ The MMS was originally modified by the Case Management Society of America (CMSA, http://CMSA. org) to enable the classification of patients by levels of motivation and knowledge as part of the CMSA's Case Management Adherence Guidelines. ${ }^{20}$ The MMS consists of the following 6 "yes" or "no" items and provides subscale scores for motivation (items 1,2, and 6) and knowledge (items 3, 4, and 5):

1. "Do you ever forget to take your medicine?"

2. "Are you careless at times about taking your medicine?"

3. "When you feel better, do you sometimes stop taking your medicine?"

4. "Sometimes if you feel worse when you take your medicine, do you stop taking it?"

5. "Do you know the long-term benefit of taking your medicine as told to you by your doctor or pharmacist?"

6. "Sometimes do you forget to refill your prescription medicine on time?"

To obtain the subscale scores, items are summed (yes $=0$ and no $=1$ ); item 5 is reverse scored (yes $=1$ and no $=0$ ). According to the CMSA, subscale scores of 0 and 1 suggest low motivation or knowledge, and scores of 2 or 3 suggest high motivation, with the range of each subscale being 0 to $3 .{ }^{20}$

All focus groups were conducted by an experienced moderator using a discussion guide consisting of open-ended questions (Appendix). During the focus group discussion, participants were first asked to describe their AF symptoms, 
general experience with $\mathrm{AF}$, and aspects of their lives affected by AF. The bulk of the discussion then focused on participants' experiences with their OA medications, including the factors that affect their adherence to these medications.

\section{Analysis and Conceptual Model Development}

In review and summary of the selected articles for the literature review, a listing of factors affecting $\mathrm{OA}$ adherence was generated, even if mentioned only once in a given study. Field notes and audio recordings from the focus groups were analyzed using content analysis, a method for systematically making inferences. ${ }^{21}$ One author (Brown, an experienced qualitative researcher) was the focus group moderator for all the groups, and another researcher (a nonauthor) served as a note taker for each group. Using the notes and recordings, the focus group moderator (Brown) identified broad themes across the focus groups. To qualify as a theme, content must have been spontaneously mentioned by 2 or more people in at least 3 of the 4 focus groups. Another author (Mordin) verified the credibility of the identified themes by listening to all audio recordings, and discrepancies were resolved through discussion.

Because the focus groups generated more specific content and themes related to the process of adherence than did the listing of factors obtained from the literature review, the focus group themes served as the initial driver for model development. One author (Brown) developed the first draft of the conceptual model, encompassing all themes from the focus groups related to OA medication adherence. Then, another author (Mordin; the primary lead for the literature review) reviewed the focus group-driven model and incorporated relevant factors from the literature review. The listing of factors generated from the literature review served to ensure that potentially important content or information was not excluded from the model. Then, a third author (Pladevall-Vila) reviewed the model. The 3 authors collaborated and came to agreement on the final model structure and the inclusion of model concepts and information.

\section{Results}

\section{Literature Review}

Nonadherence to medication is a common problem in many therapeutic areas, including in the treatment and secondary prevention of stroke. ${ }^{14}$ Many factors associated with OA use are known and recognized in the literature. The following general categories of factors associated with OA adherence among patients with AF were summarized from this literature review: disease- and drug-related; patient knowledge, beliefs, and abilities; health system-related; economic; patient-physician relationship; and patient demographic, psychosocial, and personality traits.

In the development of a new questionnaire to assess barriers to $\mathrm{OA}$ medication use among patients with $\mathrm{AF}$, Ingelgård et al. (2006) classified 41 barriers to warfarin use into 4 groups: patient medical characteristics, health care system factors, patient capability, and patient preference. ${ }^{22}$ Furthermore, Cohen et al. (2009) ${ }^{14}$ summarized factors that affect adherence to anticoagulation medication based on the study by Ingelgard et al., ${ }^{22}$ as well as 2 other studies, only 1 of which was focused specifically on OA medication adherence. ${ }^{23}$ The factors listed by Cohen et al. were related to disease (e.g., symptoms, longterm therapy, morbidities); drug (e.g., adverse events, duration, dose frequency and complexity, polypharmacy, cost); patient (e.g., lack of support, lack of disease knowledge, concerns, difficulty comprehending instructions, inability to adhere to restrictions); follow-up (e.g., shortage of time, costs associated with INR monitoring, patient unwilling to repeat testing, delay in laboratory reporting); and health system (e.g., patient-doctor relationship, reimbursement, lack of proper facilities or experience to manage therapy). ${ }^{14}$

Investigators have sought to further understand the extent of patient knowledge and the impact on adherence through the development of patient-reported outcomes questionnaires..$^{24,25}$ For example, Smith et al. (2010) examined the extent to which patients understand the modifiable factors that can affect warfarin safety and efficacy. ${ }^{24}$ A 52 -item questionnaire was administered among a convenience sample of $100 \mathrm{AF}$ patients taking warfarin and receiving care at a large clinical practice. The questionnaire involved 5 key areas: general warfarin knowledge, compliance, drug interactions, herbal or vitamin interactions, and diet. Results suggested that in general, patients on warfarin, especially those at highest risk of stroke, had a poor understanding of the medication. ${ }^{22}$

Other studies involving AF patients and OA medication have supported additional individual factors, primarily those related to patient demographics and psychosocial factors, such as age, gender, personality, and cognitive status. In the International Normalized Ratio Adherence and Genetics (IN-RANGE) Study (Platt et al. 2008), a prospective cohort study of 111 adults taking warfarin, various demographic and psychosocial factors were found to be associated with nonadherence. ${ }^{26}$ Specifically, nonadherence was greater among those with educational levels beyond high school and those currently employed (compared with those unemployed and retired). Of the psychosocial factors examined, lower levels of mental health functioning and poor cognitive functioning were associated with worse adherence. Conversely, measures of physical functioning, selfassessed overall general health, sleep quality, and depression were not associated with adherence in multivariate analyses.

A case-control study by Arnsten et al. (1997) in an anticoagulation clinic also found significant relationships between various demographic characteristics and adherence. ${ }^{23}$ Specifically, patients who had been discharged from the clinic for noncompliance (defined as discontinuing warfarin or taking warfarin with inadequate INR measurement) were more likely 
than warfarin-adherent patients to be younger (mean aged 53.7 years vs. 68.7 years), male, and nonwhite. Nonadherent patients were also more likely to report a lack of understanding or knowledge of the reason for taking warfarin and were also less likely to have a regular physician. Furthermore, nonadherent patients who did have a regular physician tended to feel more dissatisfied with their physician relationship compared with more adherent patients.

Several key psychosocial factors associated with poorer adherence have consistently emerged within the adherence literature in studies of patients with diagnoses other than AF. These factors include depressive symptoms, pessimism, and a perceived lack of social support. $11,27,28$

\section{Focus Groups}

Participants. A total of 38 participants with a mean age of 70 years participated in the 4 focus groups (ranging from 8 to 10 participants in each group). Four focus groups and this sample size were deemed appropriate and sufficient to obtain saturation, a point at which no new themes are being introduced in a qualitative methodology, suggesting that all relevant themes have been mentioned (e.g., Frost et al. 200729). The lack of additional themes generated with the third and fourth focus groups provided evidence of saturation among this nonprobability sample.

The majority of the focus group participants were white and had completed at least some college coursework (Table 1). Rates of comorbidities were generally high; among the 4 comorbidities asked of the participants (hypertension, high cholesterol, heart disease/chronic heart failure, and diabetes), participants reported an average of 2.0 conditions, and $31.6 \%$ of participants reported 3 or 4 of these conditions (data not shown in table). The majority of participants were taking warfarin ( $n=34,89.5 \%$ ). According to the MMS, $78.9 \%$ of participants reported high levels of motivation, and 100\% reported high levels of knowledge.

General Health and OA Medication. Approximately 85\% of participants reported 2 or more health conditions and indicated that they were under the care of at least 1 specialist clinician in addition to their primary care physicians. When asked about their experiences with AF, most participants reported little, if any, impact of AF on their daily lives and activities. Participants primarily had experience with the OA medication ("blood thinner") that they were currently taking and had little, if any, experience taking other OA medications in the past. Approximately $25 \%$ of participants said that their OA medication dosages frequently changed from one day or week to another because of their fluctuating and out-of-range INR measurements. Three participants (8\%) said that they routinely took a different dose 2 or 3 days of the week.

While approximately $85 \%$ of participants were aware and quick to express the purpose of their OA medication, approxi-

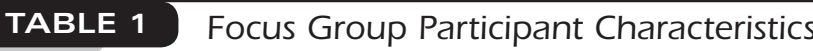
and Modified Morisky Scale Scores

\begin{tabular}{l|c}
\hline \multicolumn{2}{|c}{ and Modified Morisky Scale Scores } \\
\hline Total N & $\%$ \\
\hline Characteristics & (n) \\
\hline Sex & $52.6 \quad(20)$ \\
\hline Male & $47.4 \quad(18)$ \\
\hline Female & $70 \quad(60-82)$ \\
\hline Mean age in years (range) &
\end{tabular}

Comorbidities

\begin{tabular}{l|rl}
\hline Hypertension & 86.8 & (33) \\
\hline High cholesterol & 50.0 & (19) \\
\hline Heart disease or chronic heart failure & 31.6 & (12) \\
\hline Diabetes & 28.9 & (11) \\
\hline
\end{tabular}

Duration of anticoagulant medication use

\begin{tabular}{l|ll}
\hline Less than 5 years & 52.6 & $(20)$ \\
\hline 5 to 10 years & 31.6 & $(12)$ \\
\hline More than 10 years & 15.8 & $(6)$ \\
\hline Anticoagulant medicationa
\end{tabular}

Anticoagulant medication ${ }^{\mathrm{a}}$

\begin{tabular}{l|rl}
\hline Warfarin & 89.5 & (34) \\
\hline Clopidogrel bisulfate & 10.5 & (4) \\
\hline Aspirin/dipyridamole combination & $2.6 \quad(1)$ \\
\hline
\end{tabular}

History of stroke

\begin{tabular}{l|rc}
\hline Yes & 23.7 & $(9)$ \\
\hline No & 76.3 & $(29)$ \\
\hline Race & & \\
\hline White & 86.8 & $(33)$ \\
\hline Black & 10.5 & $(4)$ \\
\hline Hispanic & 0.0 & $(0)$ \\
\hline Asian & 0.0 & $(0)$ \\
\hline Other & 2.6 & $(1)$ \\
\hline
\end{tabular}

Education

\begin{tabular}{l|rc}
\hline Less than high school diploma & 0.0 & $(0)$ \\
\hline High school diploma/GED & 28.9 & $(11)$ \\
\hline Some college & 26.3 & $(10)$ \\
\hline College degree & 23.7 & $(9)$ \\
\hline Post-graduate coursework/degree & 21.1 & $(8)$ \\
\hline Modified Morisky Scaleb & & \\
\hline High motivation & 78.9 & $(30)$ \\
\hline Mean [SD] & 2.3 & {$[0.93]$} \\
\hline High knowledge & 100.0 & $(38)$ \\
\hline Mean [SD] & 2.8 & {$[0.39]$} \\
\hline
\end{tabular}

aCounts sum to 39 because 1 participant taking clopidogrel bisulfate also took warfarin. No exclusions for specific OA drug were made; however, some medications

(e.g., dabigatran) had no users in the focus group because of small sample size and low market share at the time of the study.

${ }^{b}$ On the Modified Morisky Scale, items 1, 2, and 6 pertain to the Motivation subscale and items 3, 4, and 5 pertain to the Knowledge subscale. Subscale items were summed to obtain the subscale score (yes $=0$ and no $=1$ ). Item 5 was reverse scored (yes $=1$ and no=0). A low subscale score is 0 or 1 , and a high score is 2 or 3 with the range of each subscale being 0 to 3 .

$G E D=$ general education diploma; $O A=$ oral anticoagulant $S D=$ standard deviation .

mately 15\% expressed uncertainty about how their OA medication was related to their AF or about AF in general.

Beliefs About OA Medication Adherence. Participants acknowledged the need to be especially careful and vigilant with taking their OA medication due to potentially serious 


\section{TABLE 2 Summary of Adherence Drivers and Barriers from Focus Groups}

\begin{tabular}{|c|c|}
\hline Theme $^{\mathrm{a}}$ & Description, Examples, and Participant Quotations \\
\hline \multicolumn{2}{|l|}{ Adherence drivers } \\
\hline $\begin{array}{l}\text { Reminders from and } \\
\text { sense of responsibility } \\
\text { to spouse or family } \\
\text { members }\end{array}$ & $\begin{array}{l}\text { - "My husband knows what I'm taking. It's good to have a backup." } \\
\text { - "It's the first thing my son says when he calls." } \\
\text { - "My children would react badly if I didn't take it. They would question why I wasn't taking it." } \\
\text { - I don't want to let them down." }\end{array}$ \\
\hline $\begin{array}{l}\text { Established, } \\
\text { personalized routine } \\
\text { or system }\end{array}$ & $\begin{array}{l}\text { Most participants were generally quite regimented in the routine they had developed and acknowledged that it was their own } \\
\text { system. For many, their consistency had increased over time to form a strong habit. } \\
\text { - Personalized ("You have to do whatever works for you.") } \\
\text { - Cueing with placement and daily routines (e.g., brushing teeth, going to bed, pill bottle beside bed) } \\
\text { - Reminders and devices (e.g., pill packs, mobile phone alerts) }\end{array}$ \\
\hline $\begin{array}{l}\text { Knowledge or } \\
\text { perceived importance } \\
\text { of adherence }\end{array}$ & $\begin{array}{l}\text { Many participants said that education and knowledge were foundational to their understanding of the importance of adherence. } \\
\text { "We're all going to leave this earth: I'm not going to die stupid." } \\
\text { Some commented that their learning was a process, and they had gained knowledge over a period of years. Other participants } \\
\text { were still seeking additional information and inquired how they could learn more. }\end{array}$ \\
\hline $\begin{array}{l}\text { Fear and avoidance } \\
\text { of nonadherence } \\
\text { consequences }\end{array}$ & $\begin{array}{l}\text { Participants often reported fear-based motivation and conscientiousness to take their oral anticoagulant. Not only do participants } \\
\text { want to live and avoid a stroke, but they also don't want to be a burden on their families. } \\
\text { - "You only have } 1 \text { heart. I'm really scared about my heart." } \\
\text { "Don't want to have a stroke." (A stroke is worse than death.) } \\
\text { - "It's a way to avoid having more surgeries or being hospitalized." }\end{array}$ \\
\hline $\begin{array}{l}\text { Being proactive and } \\
\text { organized (removal of } \\
\text { barriers) }\end{array}$ & $\begin{array}{l}\text { Many participants (mostly among females and those living alone) said that while they were not always proactive and organized } \\
\text { in all aspects of their lives, they believed that these qualities were essential to ensure medication adherence and to maintain their } \\
\text { health status. } \\
\text { "You have to be your own advocate." } \\
\text { "It's do or die." } \\
\text { "I have to be terribly proactive or else the doctors will make a mistake." } \\
\text { Another aspect of organization is the removal of barriers (e.g., } 2 \text { participants claimed to have changed their pharmacies so that } \\
\text { they could ensure medication availability when they travel; several participants mentioned the advantage of using a pill pack to } \\
\text { notice earlier when their medication needed refilling). }\end{array}$ \\
\hline \multicolumn{2}{|l|}{ Adherence barriers } \\
\hline Forgetting & Especially when out of their normal routine or when traveling \\
\hline $\begin{array}{l}\text { Carelessness, } \\
\text { insufficient planning, } \\
\text { and/or competing } \\
\text { priorities }\end{array}$ & $\begin{array}{l}\text { Did not have it with them (e.g., when traveling, working late, or out to dinner) } \\
\text { - Took the wrong day in the pill pack } \\
\text { - Forgot and took it twice } \\
\text { - Was too tired and fell asleep }\end{array}$ \\
\hline $\begin{array}{l}\text { Confusion due to } \\
\text { complex dosing }\end{array}$ & Forgot about or was confused about a new or adjusted dose (took the wrong dose) \\
\hline $\begin{array}{l}\text { Lack of knowledge } \\
\text { and motivation }\end{array}$ & $\begin{array}{l}\text { Unaware of the need or seriousness of taking the medication and taking it regularly } \\
\text { "I've taken my pill } 4 \text { hours late before, and my levels are fine." } \\
\text { - "I's not going to make that big of a difference if you miss a dose. You wouldn't be able to stop taking it for a dental cleaning if } \\
\text { it mattered that much." } \\
\text { "I'm not going to worry myself into having a stroke over one pill." }\end{array}$ \\
\hline
\end{tabular}

aAll themes (drivers and barriers) met the same criteria for frequency of report: spontaneously mentioned/supported by at least 2 people in each of 3 (of the 4) focus groups.

effects. For example, approximately $85 \%$ of participants were aware that not taking their OA medication on a regular basis could lead to a stroke and that taking too much could result in bleeding.

When asked what helps or motivates them to take their OA medication as directed, most participants reported a mixture of factors, primarily involving their own beliefs about the medication, the influence of and role played by their families or family members, and external reminders and cues. Although specific responses varied among participants, the identified focus group themes relating to daily OA medication adherence are presented in Table 2.

For nearly all participants, beliefs about OA medication were related to perceived health risks, fears, and the known consequences of not taking the OA medication as directed. Participants commented that education and knowledge were foundational to their understanding of the importance of adherence (i.e., to understand how to minimize the health risks and decrease fear). About one-half of the participants also commented that their learning was a process; they had gained knowledge over a period of years. A few others $(n=5,13.0 \%)$ stated that they were still seeking additional information and inquired how they could learn more. Additionally, for more than two-thirds of participants, family members reportedly served as motivation to take their OA medication. Participants said that they were either reminded by family members or felt 


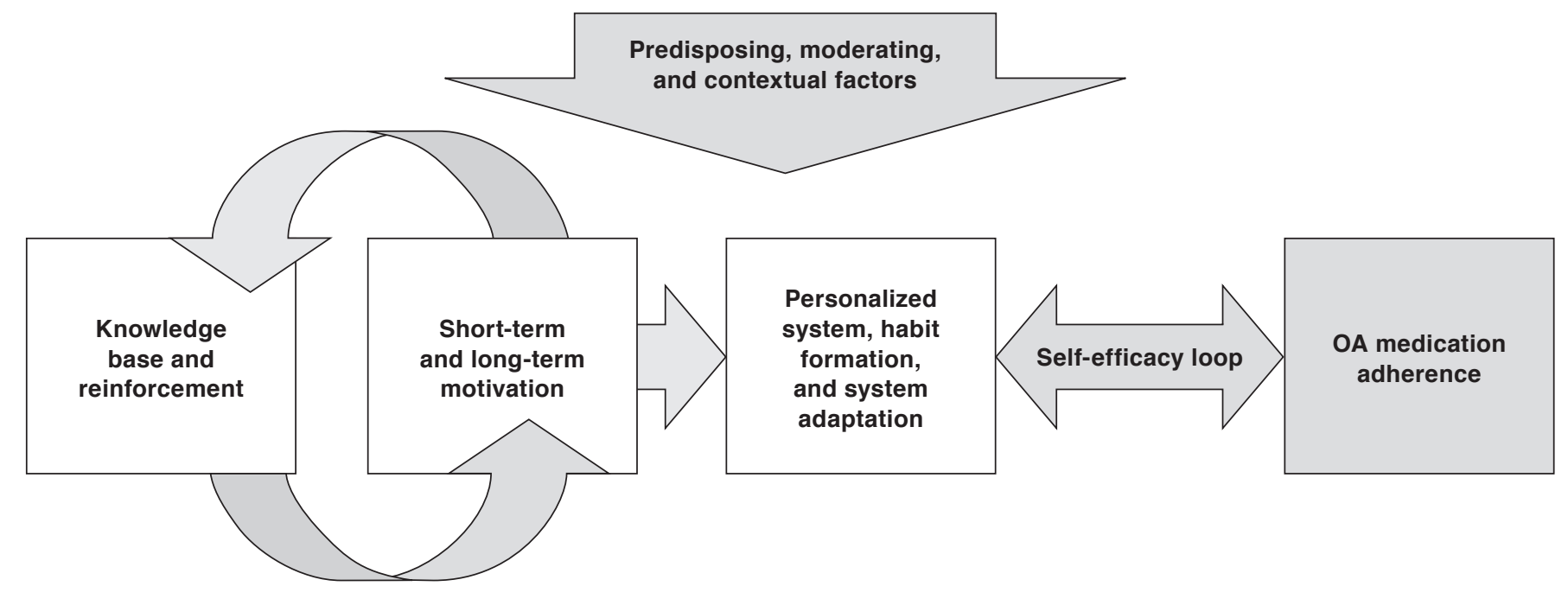

OA= oral anticoagulant.

a sense of responsibility to their family that motivated them to take care of themselves.

Nearly three-fourths of participants reported on the impact of external reminders (e.g., mobile phone alarm, placing medication on bedside table to take before bedtime) and cues (e.g., dinnertime or when the nightly news comes on television) to help them take their OA medication consistently. Participants with doses that changed from one day or week to another acknowledged that it could be confusing to "keep it straight in your head;" several of these participants referred to their "schedule" and relied heavily on their pill packs to avoid dosing mistakes. Participants referred to taking their OA medication as becoming a habit or routine. A large majority (approximately $85 \%$ ) of participants were generally quite regimented in the routine they had developed and acknowledged that it was "their" system (e.g., "You have to do whatever works for you.").

Factors mentioned less spontaneously and frequently (i.e., not qualifying as a theme), although still considered influential by the few participants who reported them, included participants' relationships and communications with their doctors and other health care providers (reported by 4 participants) and with their pharmacies (reported by 2 participants). In general, across the focus groups, participants said that their relationships with their doctors were important and even mentioned that they would switch doctors if they did not have a good rapport; however, only 4 participants spontaneously attributed taking their $\mathrm{OA}$ medication on a regular basis to their doctors, and only 2 reported a significant role by their pharmacies. In contrast, when asked about their $\mathrm{OA}$ and $\mathrm{AF}$ knowledge, participants spontaneously noted that doctors play an important and respected role as sources of health-related knowledge. Additionally, when asked specifically about running out of their OA medication, participants said that pharmacies were important in providing email or telephone reminders.

Beliefs About OA Medication Nonadherence. Nearly all participants $(n=35)$ initially expressed the belief that they were always consistent in taking their OA medication and getting their blood drawn as required for INR monitoring. In fact, only 3 participants of the 38 were initially forthcoming in admitting that they sometimes intentionally did not take their OA medication. However, as the group discussions continued, nearly one-half of the participants revealed that they on occasion missed a dose of their OA medication, were late to refill their prescriptions, or rescheduled their blood tests. These participants ranged in their report of missed or late doses from 2 per week at most to once every 2 months. Some of the reasons and explanations frequently provided by participants are listed in Table 2.

Participants were fully aware that, if they missed a dose, they were to wait until the next dose and never double the dose. However, $90 \%$ of participants were less knowledgeable about the appropriate window of time to take their medication and varied in their assumptions about how early or late they could take their medication (e.g., anywhere from 1 to 4 hours). No participant knew for sure or claimed to have obtained this information from a health care provider or other credible source. About one-quarter of participants expressed the belief that delaying or randomly missing a dose would not lead to serious consequences, especially if their INR levels continued 


\section{TABLE 3 Summary of Conceptual Model Factors and Processes}

\begin{tabular}{|c|c|}
\hline Factor or Process & Description \\
\hline Knowledge base and reinforcement & $\begin{array}{l}\text { - May require years of education and knowledge building } \\
\text { - Reinforcing role of health care provider } \\
\text { - Understanding long-term need and purpose of oral anticoagulant } \\
\text { - Understanding importance of adherence and what is nonadherence } \\
\text { - Incorporation/involvement of family/caregiver }\end{array}$ \\
\hline Short-term and long-term motivation & $\begin{array}{l}\text { - Perceived health risks and consequences of nonadherence (e.g., death, stroke, being a burden on family) } \\
\text { - Incorporation/involvement of family/caregiver }\end{array}$ \\
\hline $\begin{array}{l}\text { Personalized system, habit formation, } \\
\text { and system adaptation }{ }^{\mathrm{a}}\end{array}$ & $\begin{array}{l}\text { - Identification and removal or minimization of barriersa } \\
\text { - Reminders or feedback to address forgetting, re-taking, and dose changes } \\
\text { - Incorporation of family or external reminders } \\
\text { - Organizational skill development }\end{array}$ \\
\hline $\begin{array}{l}\text { Self-efficacy loop and oral anticoagulant } \\
\text { adherence }\end{array}$ & $\begin{array}{l}\text { - Patients' personalized systems are reinforced as their adherence efficacy increases. } \\
\text { - Patients become more and more confident in their systems, their abilities to be consistent and regimented, } \\
\text { and their abilities to adapt their systems as needed. }\end{array}$ \\
\hline $\begin{array}{l}\text { Other factors } \\
\text { (predisposing, moderating, and } \\
\text { contextual factors decreasing } \\
\text { adherence) }\end{array}$ & $\begin{array}{l}\text { - Younger than } 65 \text { years/full-time employment } \\
\text { - Males/nonwhite males } \\
\text { - Highly educated (i.e., more than high school) } \\
\text { - Financial difficulties (e.g., copayments) } \\
\text { - Personality/attitude/value system (e.g., pessimism) })^{\mathrm{b}} \\
\text { - Mental health issues (e.g., depression) } \\
\text { - Cognitive deficits } \\
\text { - Perceived lack of social support } \\
\text { - Poor relationship or dissatisfaction with health care professional }\end{array}$ \\
\hline
\end{tabular}

a Denotes a factor that was not specifically supported by the literature review but included in the model based on focus group themes.

${ }^{b}$ Denotes a factor or aspect of a factor that was not mentioned or sufficiently supported by focus group participants but included in the model based on the literature review.

to be stable. Participants with frequently changing doses were hesitant to admit to accidentally taking the wrong dose from time to time, but when asked directly, they said that it was possible and that they may even be unaware of times that they took the wrong dose.

Of note, this sample of AF participants, including a majority of generic OA medication users (26 participants reported using warfarin; 8 used brand warfarin; 4 used clopidogrel; and 1 used aspirin/dipyridamole combination), did not generally consider cost to be a factor influencing the regularity and consistency with which they take their OA medication. When asked directly about costs, participants said that cost could very easily be a problem for other patients, but they did not perceive it as a barrier for themselves. Less than 10\% of participants reported switching from brand warfarin to generic warfarin due to costs and/or insurance reasons.

\section{Conceptual Model}

The themes and adherence process summarized from the focus groups, and supported and augmented by the literature review, were summarized into a conceptual process: knowledge base and reinforcement; short-term and long-term motivation; personalized system, habit formation, and system adaptation; and OA medication adherence and the self-efficacy loop. The conceptual model is shown in Figure 2, and explanatory descriptions are provided in Table 3. Factors outside of the adherence process, although still important in explaining individual adherence and nonadherence differences, were noted as "other" factors, including various demographic and psychosocial elements. These other factors, largely based on the literature review, may serve a predisposing, moderating, and/or contextual role in the adherence process and vary from patient to patient.

The model starts with the patient's knowledge base about AF and the need to take OA medication, which requires reinforcement of this knowledge so that the patient (and/or caregiver or family member) maintains his or her perception and beliefs related to the importance of taking his or her OA medication. From knowledge comes motivation, which is both a product and driver of knowledge. As in the information-motivation-behavioral (IMB) skills model, which was developed by Fisher and Fisher (2002) to guide thinking about complex health behaviors, the presence of both information and motivation increases the likelihood of behavioral change (e.g., habit formation and system adaptation) and/or adherence. ${ }^{30}$ In order for patients (and/or their caregivers or family members) to stay motivated, their knowledge base (the cognitive element of the model) must be maintained (i.e., knowledge is the source or resource for the emotions required for motivation). In the focus groups, patients reported being highly motivated by their own knowledge, such as information about OA nonadherence consequences.

The tools of knowledge and motivation form a foundation for behavioral action and changes involved in the reminder system. To remain effective in supporting adherence, this 
personalized system will need revising and adjusting as time passes and needs change (e.g., patient, family, environmental, and health changes). For example, daily routines and behaviors, priorities, and levels of social support (e.g., family involvement) are likely to change over time, which may warrant adjustments in the system (e.g., the use of a different daily reminder, alarm, or cue).

According to the model, there is a trial-and-error loop that will support the patient's self-efficacy (or confidence) and, ultimately, overall OA medication adherence. This loop can provide positive, reinforcing feedback or serve to suggest necessary adjustments and updates if adherence is not maintained. Simply put, this loop provides positive or negative feedback and informs the patient to either stick with the system or make a change. Note that the reinforcing effect of this self-efficacy loop is contingent upon an educated and motivated patient (and/or caregiver or family member), and the activity and role of this loop will likely change over time (e.g., for a new patient vs. one who has been taking an OA medication for years). Additionally, the role and need for this loop will vary among individual patients based on their unique needs.

Further acknowledging that each patient with $\mathrm{AF}$ is different, sitting at the top of the model are a number of predisposing, moderating, and contextual factors. While the model does not fully articulate the role of each of these many factors, any 1 or more of these factors can potentially influence any given patient with AF and his or her OA medication adherence.

\section{Discussion}

The conceptual model developed in this study depicts a general process of OA medication adherence as created primarily from the perspective of the patient. With further support and addition of various factors affecting adherence to warfarin obtained from the literature, this conceptual model exemplifies a path that also includes the complexities of the OA adherence process. Many factors are involved in this process, including patient knowledge about the disease and its treatment, the patients' own beliefs and fears, and the unique reminder systems and routines that patients develop to help them form a habit and consistently remember to take their OA medication as directed. Furthermore, this model also allows for a number of other idiosyncratic factors, such as patient age, gender, personality, financial status, level of social support, and cognitive functioning. While these factors are not explained by the model, it is acknowledged that the OA adherence process is complex and will likely be affected by one or more of these factors.

To our knowledge, this study of adherence to OA medication is the first to incorporate the patient perspective as it relates to understanding the $\mathrm{OA}$ medication adherence process. Specifically, one unique aspect of the model is that it was driven and supported primarily by patient feedback (e.g., information about personalized systems, habit formation, and system adaptation). The conceptual model purports that a medication-taking system is unique to each patient, and it is critical that each patient be actively involved in the development, maintenance, monitoring, and adaptation of this system (or habit). The model also suggests the importance of family and caregiver involvement with this system. While the value of social support and the use of reminder systems such as pill packs (pill cases or pill boxes) are not new to the OA medication adherence literature or to adherence programs generally (e.g., Volpp et al. $2008^{31}$ ), the unique contribution of this study to this concept involves the patient report of system personalization, ownership, and adaptation.

This conceptual model can guide thinking and decisions related to the complex and idiosyncratic process of OA medication adherence. In the application of this model, OA adherence program developers may consider multiple potential modules or aspects of a new program. One program module could be an educational component designed to inform patients on a number of elements related to OA medication. In the current study, focus group participants stressed the importance of knowledge. The literature review also supported the role of knowledge and need for educational programs (e.g., Smith et al. 2010:24 Zeolla et al. 2006; ${ }^{25}$ and Prins et al. 200932). However, other studies have not found a positive relationship between patient knowledge and warfarin medication outcomes (e.g., Baker et al. $2011^{33}$ and Davis et al. 2005 ${ }^{19}$.

Despite these inconsistencies, the focus group participants in the current study spontaneously stressed the importance of knowledge for their own OA medication adherence, that learning was a process that took time, and that some patients were still looking to increase their knowledge. Some participants also expressed their own need for education pertaining to how their OA medication related to AF and the appropriate daily time frame in which to take their OA medication. Furthermore, participants associated their own level of knowledge with adherence as well as with their own motivation to stay adherent. The proposed educational module could detail key information about the disease, its course, the treatment involved, the importance of adherence, and what constitutes nonadherence. This information could be delivered at multiple time points and in multiple ways (e.g., upon diagnosis; upon prescription fill and refill; and by nurse, doctor, pharmacist, or family member). Another consideration could be the way in which patients prefer receiving this information, such as through printed media, verbal face-to-face communication, or via telephone from a dedicated adherence coach.

Results from the focus groups suggested that some patients may not realize or admit that they are nonadherent with their OA medication. Another module of an adherence program could detail the key communications necessary between the patient and health care provider or coach to uncover potential 
nonadherence issues. Furthermore, assessing family support and patient beliefs and attitudes will be important in determining the patient's level of motivation over time. Additionally, patients will vary in their abilities and capacities to develop, maintain, and adapt the behavioral skills necessary for OA medication adherence. A multidimensional adherence program will need not only to educate patients (and their caregivers or families) and assess potential attitudinal barriers, but also to train, assess, and re-train patients in their personalized behavior systems. This module of the program, as with any module, will change depending on the patient's needs, preferences, beliefs, and duration on OA medication.

Some elements of the conceptual model were supported by the literature review but not by patient feedback in the focus groups. Specifically, 2 of these factors are the impact of costs and the physician/provider-patient relationship on daily OA medication adherence. While these elements were not explicitly mentioned in the patient groups as key barriers to $\mathrm{OA}$ adherence, we believe, based on published research, in the importance of including these factors in the conceptual model. ${ }^{22,23,32}$ One explanation for the lack of discussion within the focus groups about these factors may be specific to the characteristics of this patient sample. For the cost component, the majority of the focus group participants were taking warfarin, a relatively low-cost generic medication with out-of-pocket costs often ranging from $\$ 4$ to $\$ 10$ per month. Furthermore, because all of the focus group participants reported positive relationships with their health care providers, it seems reasonable that this sample of patients with AF would not refer to these relationships as barriers to OA adherence.

\section{Limitations}

First, although focus group data are recognized for explaining and exploring how individuals think, a focus group sample is not designed to be representative. To strengthen this design, the synthesis of results from the accompanying literature review was used to support, in part, results from the focus groups in generating the conceptual model.

Second, there was likely a selection bias for the focus group sample. One could argue that individuals who choose to participate in a focus group may be more likely to be outgoing, healthy, knowledgeable, and motivated than nonparticipants. While patient characteristics in the current study were generally similar to those in the study by Smith et al., ${ }^{24}$ it is possible that the focus group participants may not be representative of all OA medication users in their levels of knowledge and motivation. We believe that this bias may have actually benefited the current study; the focus group participants were engaged and forthcoming in providing information related to both the drivers of and barriers to OA medication adherence and could clearly articulate them. While less knowledgeable or motivated individuals may be less adherent and their barriers may vary from those of the focus group, we propose that this conceptual model depicts a process of OA medication adherence that is relevant for those at varying levels of adherence.

Third, the current study focused on OA medication adherence; it did not focus on INR testing adherence. The study also relied primarily on the experiences of patients taking warfarin; it did not use the experiences of patients on other types of OA medication. The purpose of the medication adherence focus was not to ignore the additional components of frequent laboratory monitoring but to develop a corresponding conceptual model of OA medication adherence. Furthermore, the emphasis placed solely on warfarin was not planned but attributable to the relatively recent approval of other OA medications and the abundant and long-standing use of warfarin, in both its generic and brand name forms. Because this conceptual model of the general OA medication adherence process, developed primarily from warfarin users and the published literature, involves factors and processes very similar to those observed in the adherence process for other disease states, it would also seem relevant in defining and describing the adherence process of other types of OA medication.

\section{Conclusion}

Although factors associated with OA medication adherence have been identified in previous research, this study is the first to capture and conceptualize the patient perspective as it relates to the OA medication adherence process. Based on patient feedback, for patients to remain adherent to OA medication, they need to develop and adapt their own personal systems for taking OA medication. This conceptual model supports the need for a multidimensional patient adherence program for OA medication and could be used to assist in the identification and planning of such a program.

\section{Authors}

T. MICHELLE BROWN, PhD, is Director; MANEL PLADEVALLVILA, MD, MS, is Director; and MARGARET MORDIN, MS, is Senior Director, RTI Health Solutions, Research Triangle Park, North Carolina. KIMBERLY SIU, MD, MPH, is Manager; DAVID WALKER, PhD, is Associate Director; and STEPHEN SANDER, PharmD, is Director, Boehringer Ingelheim Pharmaceutical Inc., Ridgefield, Connecticut.

AUTHOR CORRESPONDENCE: T. Michelle Brown, PhD, RTI Health Solutions, 200 Park Offices, Rm. 251, Research Triangle Park, NC 27709. Tel.: 919.541.7156; Fax: 919.541.7222;

E-mail:tmbrown@rti.org. 


\section{DISCLOSURES}

This work was supported by Boehringer Ingelheim Pharmaceuticals, Inc. (BIPI), the developer of dabigatran etexilate, recently approved for the treatment of stroke risk reduction in nonvalvular atrial fibrillation. Brown, Mordin, and Pladevall-Vila are employees of RTI Health Solutions and were paid consultants to BIPI in connection with the development of the article. Siu, Walker, and Sander are full-time employees of BIPI. The authors meet criteria for authorship as recommended by the International Committee of Medical Journal Editors (ICMJE), were fully responsible for all content and editorial decisions, and were involved at all stages of manuscript development.

Concept and design were performed primarily by Sander, Siu, and Walker with the assistance of Brown and Mordin. The data were collected primarily by Brown and Mordin and analyzed by Brown and Mordin with the assistance of the other authors. The manuscript was written primarily by Brown, Siu, and Mordin and revised primarily by Brown and Pladevall-Vila.

\section{ACKNOWLEDGEMENTS}

The authors thank Alyssa Dallas, BS, of RTI Health Solutions for editorial assistance and Rachel Police, MPH, of RTI Health Solutions for note-taking assistance during the focus group sessions.

\section{REFERENCES}

1. Naccarelli GV, Varker H, Lin J, Schulman KL. Increasing prevalence of atrial fibrillation and flutter in the United States. Am J Cardiol. 2009; 104(11):1534-39.

2. Ryder KM, Benjamin EJ. Epidemiology and significance of atrial fibrillation. Am J Cardiol. 1999;84(9A):131R-138R.

3. Wattigney WA, Mensah GA, Croft JB. Increasing trends in hospitalization for atrial fibrillation in the United States, 1985 through 1999: implications for primary prevention. Circulation. 2003;108(6):711-16. Available at: http:// circ.ahajournals.org/content/108/6/711.long. Accessed May 16, 2012.

4. Wolf PA, Abbott RD, Kannel WB. Atrial fibrillation as an independent risk factor for stroke: the Framingham Study. Stroke. 1991;22(8):983-88. Available at: http://stroke.ahajournals.org/content/22/8/983.long. Accessed May 16, 2012.

5. Rose AJ, Ozonoff A, Grant RW, Henault LE, Hylek EM. Epidemiology of subtherapeutic anticoagulation in the United States. Circ Cardiovasc Qual Outcomes. 2009;2(6):591-97. Available at: http://circoutcomes.ahajournals. org/content/2/6/591.full.pdf+html. Accessed May 16, 2012.

6. Jones M, McEwan P, Morgan CL, Peters JR, Goodfellow J, Currie CJ. Evaluation of the pattern of treatment, level of anticoagulation control, and outcome of treatment with warfarin in patients with non-valvar atrial fibrillation: a record linkage study in a large British population. Heart. 2005;91(4):472-77. Available at: http://heart.bmj.com/content/91/4/472.full. Accessed May 16, 2012.

7. De Schryver EL, van Gijn J, Kappelle LJ, Koudstaal PJ, Algra A; Dutch TIA trial and SPIRIT study groups. Non-adherence to aspirin or oral anticoagulants in secondary prevention after ischaemic stroke. J Neurol. 2005;252(11):1316-21

8. Gulløv AL, Koefoed BG, Petersen P. Bleeding during warfarin and aspirin therapy in patients with atrial fibrillation: the AFASAK 2 study. Atrial Fibrillation Aspirin and Anticoagulation. Arch Intern Med. 1999;159(12):1322-28. Available at: http://archinte.ama-assn.org/cgi/content/full/159/12/1322. Accessed May 16, 2012.

9. Petty GW, Brown RD Jr, Whisnant JP, Sicks JD, O'Fallon WM, Wiebers DO. Frequency of major complications of aspirin, warfarin, and intravenous heparin for secondary stroke prevention. A population-based study. Ann Intern Med. 1999;130(1):14-22. Available at: http://www.annals.org/content/130/1/14.full.pdf. Accessed May 16, 2012
10. Budnitz DS, Lovegrove MC, Shehab N, Richards CL. Emergency hospitalizations for adverse drug events in older Americans. N Engl J Med. 2011;365(21):2002-12.

11. Osterberg L, Blaschke T. Adherence to medication. N Engl J Med. 2005;353(5):487-97.

12. Reynolds MR, Shah J, Essebag V, et al. Patterns and predictors of warfarin use in patients with new-onset atrial fibrillation from the FRACTAL Registry. Am J Cardiol. 2006;97(4):538-43.

13. Parker CS, Chen Z, Price M, et al. Adherence to warfarin assessed by electronic pill caps, clinician assessment, and patient reports: results from the IN-RANGE study. J Gen Intern Med. 2007;22(9):1254-59. Available at: http://www.ncbi.nlm.nih.gov/pmc/articles/PMC2219760/. Accessed May 16, 2012.

14. Cohen AT, Maillardet L, Yavin Y. Will a once-weekly anticoagulant for the treatment and secondary prevention of thromboembolism improve adherence? Thromb Haemost. 2009;101(3):422-27.

15. Wilson IB, Cleary PD. Linking clinical variables with healthrelated quality of life. A conceptual model of patient outcomes. JAMA. 1995;273(1):59-65.

16. Murray MD, Morrow DG, Weiner M, et al. A conceptual framework to study medication adherence in older adults. Am J Geriatr Pharmacother 2004;2(1):36-43.

17. Go AS, Hylek EM, Phillips KA, et al. Prevalence of diagnosed atrial fibrillation in adults: national implications for rhythm management and stroke prevention: the AnTicoagulation and Risk Factors in Atrial Fibrillation (ATRIA) Study. JAMA. 2001;285(18):2370-75. Available at: http://jama.amaassn.org/content/285/18/2370.long. Accessed May 16, 2012.

18. Morisky DE, Green LW, Levine DM. Concurrent and predictive validity of a self-reported measure of medication adherence. Med Care. 1986;24(1):67-74.

19. Davis NJ, Billett HH, Cohen HW, Arnsten JH. Impact of adherence, knowledge, and quality of life on anticoagulation control. Ann Pharmacother. 2005;39(4):632-36.

20. Case Management Society of America (CMSA). CMAG: Case management adherence guidelines. Guidelines from the Case Management Society of America for improving patient adherence to medication therapies. Version 2.0. June 2006. Available at: http://www.cmsa.org/portals/0/pdf/CMAG2 pdf. Accessed May 16, 2012.

21. Neuendorf KA. The Content Analysis Guidebook. Thousand Oaks, CA: Sage Publications, Inc.; 2002.

22. Ingelgård A, Hollowell J, Reddy P, Gold K, Tran K, Fitzmaurice D. What are the barriers to warfarin use in atrial fibrillation? Development of a questionnaire. J Thromb Thrombolysis. 2006;21(3):257-65.

23. Arnsten JH, Gelfand JM, Singer DE. Determinants of compliance with anticoagulation: a case-control study. Am J Med. 1997;103(1):11-17.

24. Smith MB, Christensen N, Wang S, et al. Warfarin knowledge in patients with atrial fibrillation: implications for safety, efficacy, and education strategies. Cardiology. 2010;116(1):61-69.

25. Zeolla MM, Brodeur MR, Dominelli A, Haines ST, Allie ND. Development and validation of an instrument to determine patient knowledge: the oral anticoagulation knowledge test. Ann Pharmacother. 2006;40(4):633-38

26. Platt AB, Localio AR, Brensinger CM, et al. Risk factors for nonadherence to warfarin: results from the IN-RANGE study. Pharmacoepidemiol Drug Saf. 2008;17(9):853-60. Available at: http://www.ncbi.nlm.nih.gov/pmc/articles/ PMC2919157/?tool=pubmed. Accessed May 16, 2012

27. Cruess DG, Localio AR, Platt AB, et al. Patient attitudinal and behavioral factors associated with warfarin non-adherence at outpatient anticoagulation clinics. Int J Behav Med. 2010;17(1):33-42. 
28. Rieckmann N, Gerin W, Kronish IM, et al. Course of depressive symptoms and medication adherence after acute coronary syndromes: an electronic medication monitoring study. J Am Coll Cardiol. 2006;48(11):221822. Available at: http://content.onlinejacc.org/cgi/reprint/48/11/2218.pdf. Accessed May 16, 2012.

29. Frost MH, Reeve BB, Liepa AM, Stauffer JW, Hays RD; Mayo/FDA Patient-Reported Outcomes Consensus Meeting Group. What is sufficient evidence for the reliability and validity of patient-reported outcome measures? Value Health. 2007;10(Suppl 2):S94-S105.

30. Fisher JD, Fisher WA. The information-motivation behavioral skills model. In: DiClemente RJ, Crosby RA, Kegler MC, eds. Emerging Theories in Health Promotion Practice and Research: Strategies for Improving Public Health. Indianapolis, IN: Jossey-Bass, Inc; 2002.
31. Volpp KG, Loewenstein G, Troxel AB, et al. A test of financial incentives to improve warfarin adherence. BMC Health Serv Res. 2008;8:272. Available at: http://www.biomedcentral.com/1472-6963/8/272. Accessed May 16, 2012.

32. Prins MH, Marrel A, Carita P, et al. Multinational development of a questionnaire assessing patient satisfaction with anticoagulant treatment: the 'Perception of Anticoagulant Treatment Questionnaire' (PACT-Q). Health Qual Life Outcomes. 2009;7:9. Available at: http://www.ncbi.nlm.nih.gov/ pmc/articles/PMC2654430/?tool=pubmed. Accessed May 16, 2012.

33. Baker JW, Pierce KL, Ryals CA. INR goal attainment and oral anticoagulation knowledge of patients enrolled in an anticoagulation clinic in a Veterans Affairs medical center. J Manag Care Pharm. 2011;17(2):133-42. Available at: http://www.amcp.org/data/jmcp/133-142.pdf.

\section{APPENDIX Focus Group Guide for Development of a Conceptual Model of Adherence to Oral} Anticoagulants to Prevent Stroke in Patients with Nonvalvular Atrial Fibrillation

General Health and Experience with Atrial Fibrillation

- How many prescription medications do you take every day?

- Do you consider some of your medications more important than others? Why? How important is your anticoagulation medicine compared to the others you take?

- How long have you been diagnosed with atrial fibrillation?

- Does your atrial fibrillation impact your life in any way?

- Are there any things that you would like to do that you can't do or are difficult because of atrial fibrillation?

Anticoagulation Background and Experience

- Prior to the anticoagulant drug that you take now, have you ever taken one in the past? Which ones? For how long?

- Which one do you take now? How long? How often taken? Does your dosing ever change? Why?

- Tell me about your experiences taking this medicine.

Anticoagulation Adherence

- What helps or keeps you taking this medication from day to day?

- What factors "help" or contribute to your not missing a dose of this medicine?

- What factors "help" or contribute to your taking this medicine at the same time every day?

- What or who motivates you to take your anticoagulation medicine as prescribed?

- What do you think is the main reason you take your anticoagulation medicine regularly?

- What do you believe is the long-term benefit?

- Also, what helps or keeps you going to the clinic/your doctor to get the monitoring blood tests done?

Anticoagulation Nonadherence

- Do you ever not take your medication as prescribed? Tell me more about that.

- Has your doctor, nurse, or pharmacist ever said anything to you about not taking your medicine as prescribed? What did they say? How did that make

you feel? How did that influence you taking your medicine as prescribed, if at all?

- What would be more helpful for the doctor, nurse, or pharmacist to say that would make you feel more motivated to take the medicine? What should a doctor, nurse, or pharmacist not say or do?

- What things, if any, get in the way of you taking your anticoagulation medicine every day as prescribed?

- What things, if any, get in the way of your taking it at the same time every day?

- Do you ever choose not to take it?

- Do you ever accidentally take the wrong dose or take a different dose than what is prescribed? Why do you think that happens?

- Do you think you are sometimes too casual or relaxed about taking this medicine as prescribed? Why?

- Do you ever miss or delay a visit to your doctor's office (or clinic) to have your blood drawn to monitor the level of the medicine in your blood? Why?

- Think back to the time when you first started taking this medication. Are you more or less consistent, or about the same, with your practice in taking this medicine today? Why? What changed? When did this happen?

- Since you started your anticoagulant medication, are you more or less consistent, or about the same in your clinic/doctor visits for blood tests? Why? What changed? When did this happen?

-What, if anything, could help you to take your anticoagulant medication more consistently? 